\title{
REVIEW OF LANDFILLS IN EUROPE ACCORDIND TO THE EUROPEAN COMMISSIN'S POLICY IDENTIFYING EFFECTIVE CRITERIA FOR REDUCIND, REUSING, AND PROPOSING WASTE LEVELS IN THE CONSTRUCTION SECTOR
}

\author{
H. Babaeyan Ahmadi ${ }^{a^{*},}$ J. Gallego Sánchez-Torija ${ }^{\text {a }}$ \\ ${ }^{a}$ Departamento de Construcción y Tecnología Arquitectónicas, Escuela Técnica Superior de Arquitectura \\ Universidad Politécnica de Madrid; E-mails: *h.babaeyanahmadi@alumnos.upm.es, jorge.gallego@upm.es
}

Received: 26.01.2021 / Accepted: 15.02.2021 / Revised: 07.04.2021 / Available online: 31.05.2021

DOI: $10.2478 /$ jaes-2021-0001

KEYWORDS: Landfill, Construction waste demolition (CDW), Reusing construction waste, Recycling construction waste, strategies of EU for construction waste, Inert and non-inert material.

\begin{abstract}
:
Construction waste makes up a large part of the waste produced in Europe. Therefore, the European Commission has developed policies to create an economic cycle and increase waste recycling. These solutions have been developed reduce the destructive effects of the environment, including various certificates such as LEED in different countries to encourage building debris management. However, not all construction waste can be recycled and reused, often buried in the environment. Although these wastes are extracted from natural resources, the process of making them changes their original nature, and it is not possible to estimate the exact time of their decomposition and reversibility of waste in nature. Thus, a large part of them is landfilled due to their Non-Recyclability. Moreover, every year, a large area of fertile and usable land is allocated for their burial. This paper aims to clarify the non-recyclable part of landfilled construction waste in the environment, highlighting the need for importance and research in this area. It can improve and preserve the sources, land, and health of the environment and human beings in EU member states threatened by landfilling.
\end{abstract}

\section{INTRODUCTION}

About a third (Commission, EU Construction \& Demolition Waste Management Protocol, 2016) of the waste produced in the European Union (EU) is from the Construction and Demolition (C\&D) sector, and accurate knowledge of hazardous and non-hazardous waste and its proper separation will increase the quality of life in which serves the main interests of the European Union.

The current construction sector in the European Union is 820 million tonnes. It produces waste each year from construction and demolition waste (CDW), which is about $46 \%$ of the total waste produced by statistics (Eurostat, Generation of waste by waste category, hazardousness and NACE Rev. 2 activity, 2017).

The average degradation index of construction and demolition waste (CDW), which accounts for 86\% (del Río Merino, 2010) of construction waste generated by excavations, is concrete $12 \%$, brick, ceramic 54\%, and stone 5\% however, it can be heterogeneous (CDW), including high amounts of wood $4 \%$ and gypsum $0.2 \%$ and glass 1.5 , metal $2.5 \%$, rubbish $7 \%$. Most organic materials are known to be ineffective due to their easy degradability and are not considered in (CDW) excavations due to their small impact on the environment. This amount was about 300 million $\mathrm{Mg}$ of (CDW) in 2014 in Europe. (Commission, EU Construction \& Demolition Waste Management Protocol, 2016).

The environmental impact associated with (CDW) is a major concern because it has devastating effects on logistics and land occupation. Landfill caused by C\&D can spread environmental pollution such as water pollution, including groundwater resources, and the destruction of fertile land, contamination caused by landfill and non-degradability can pose a serious threat to the animals' living environment and endanger human health. Therefore, (CDW) management is a priority in most environmental programs in the world. In the European Commission (Eurostat, Sustainable development in the European Union-2015 monitoring report of the EU Sustainable, 2015), it is proposed that by 2020, conditions for re-use, recycling, backfilling of non-hazardous (CDW) are done (Commission, Directive of the european parliament and of the council-Amending Directive 2008/98/EC on waste, 2015).

According to Category 170504 soils (including soils removed from excavated sites) and rocks that do not contain hazardous

\footnotetext{
* Corresponding author: Hamidreza Babaeyan Ahmadi, E-mail: h.babaeyanahmadi@alumnos.upm.es.
} 
materials, waste should be increased in this list to less than $70 \%$ by their weight (Arm, 2015).

The new solution requires tools and approaches for (CDW) management, while a $70 \%$ recycling rate is recommended for non-hazardous materials (Bio i. s., 2011). Although this amount of recycling is costly and ambitious for waste from building demolition, the issue of landfill non-recyclable construction waste should be further investigated. It also looked at energy consumption from recycling and landfill pollution.

It should be considered that the national conditions in European member states are inconsistent, and such a goal could be unmotivated for the industry of countries or regions where recycling is currently more than $70 \%$ (Carven, 2015).

Against this backdrop, the goal is to share better methods and approaches in developing new policies and strategic frameworks for the construction sector to help achieve the goals of developing sustainable strategies (Eurostat, Sustainable development in the European Union-2015 monitoring report of the EU Sustainable, 2015).

According to the latest statistics, this article examines the level of (CDW) production in the European Union. It also examines the amount of construction waste generated byC\&D in two parts, recyclable and non-recyclable, and the reduction of landfills in the European Union will be compared according to the indicators presented in recent years. It offers a way to re-use for non-recyclable construction waste to reduce their landfill, and it deals with two successful policies in two European countries that have resulted in a reduction in landfills in both.

\section{THE RATE OF RECOVERY AND CONSTRUCTION DEMOLITION WASTE IN EUROPEAN COUNTRIES}

\subsection{The rate of recovery and recycling of (CDW) in European countries during 2010-2018}

There is currently no reliable new information on the exact extent of $C \& D$ waste recovery in the European Union, the only policy which the European Commission has outlined for 2020. In fact, the latest reliable information and data are from the recovery and recycle of $(\mathrm{CDW})$ from the EUROSTAT (Eurostat, Recovery rate of construction and demolition waste, n.d.). However, it is worth noting that by examining the statistics provided by the EUROSTAT site between 2010, 2012 and 2012 to 2014 and 2014 to 2016 and 2016 to 2018, the available information and reliable information is only from some EU countries and a number of 27 European countries during these years. He did not give an exact estimate of the rate of recovery and recycling and waste that requires more transparency in this area.

Figure 1 of EUROSTAT indicate an increase in the recovery and recycling of the waste in countries in the region, especially in the EU (Bio i. s., 2011).
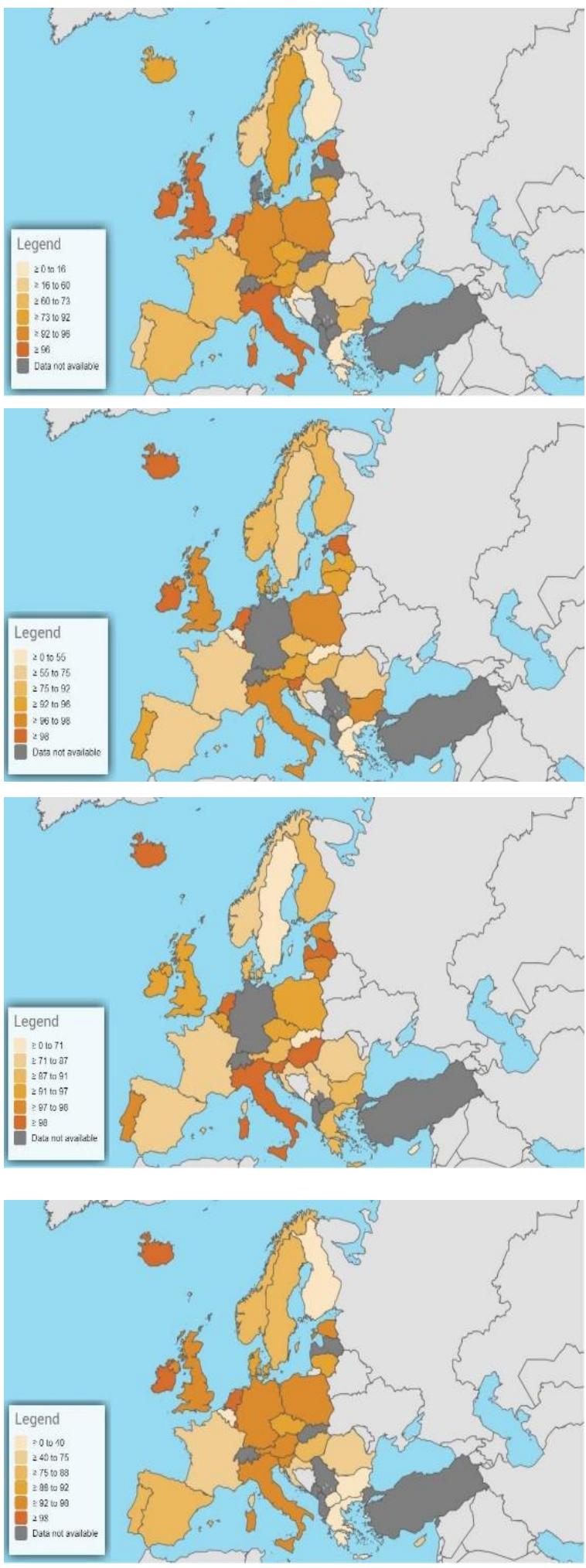

Figure 1. The recovery rate of CDW Europa 2012, 2014, 2016, 2016 (respectively) 
Regarding the recovery of materials, it should be noted that the amount of recycling to provide conditions for material recovery are the same as Re-use, Recycle, and others. According to the lesions, they are defined as the most credible information received from two governmental sources (UBA, 2009) \& (ETC/RWM, 2008).

They provide a $\mathrm{C} \& \mathrm{~W}$ waste recycling and disposal rate but have inconsistencies. It is due to the fact that the information available by EUROSTAT or questionnaires sent to member states of European countries (MS) has several inconsistencies regarding the definition of $\mathrm{C} \& \mathrm{D}$ waste. In some cultivars, excavation is considered, while in others, it is not. For example, the statistics announced by these two institutions for Germany are as follows: Germany generates 73 million tonnes of $\mathrm{C} \& \mathrm{D}$ waste without excavation soil (UBA, 2009) and 192 million tonnes with excavation soil (ETC/RWM, 2008).

In general, it does not seem easy to calculate $C \& D$ for recycling across Europe. According to the recycling rate announced by
(UBA, 2009) for 16 European countries (Bio i. s., 2011), which makes up $64 \%$ of the total of European Union, the C\&D rate for waste recycling has been reported by (ETC/RWM, 2008) for 17 European countries. In both cases, the average recycling rate for countries that have identified and made available the amount of recycling information is $86 \%$ (UBA, 2009) and $66 \%$ (ETC/RWM, 2008), respectively.

The European Union has developed guidelines for its main policies to achieve $70 \%$ readiness for Re-use, recycle, and other forms of material recovery of $C \& D$ waste. Therefore, recovery and recycling should be considered an important challenge for EU member states, as not all member states have developed policies in their national program to increase (CDW) recovery rates. Moreover, there are different indicators for $\mathrm{C} \& \mathrm{D}$ recovery rates in European countries that require strict and encouraging rules for recycling and recovery $\mathrm{C} \& \mathrm{D}$ and severe fines for landfill. The latest published statistics from EUROSTAT for 2016 (Figure 2) show the recovery trend of CDW in Europe.

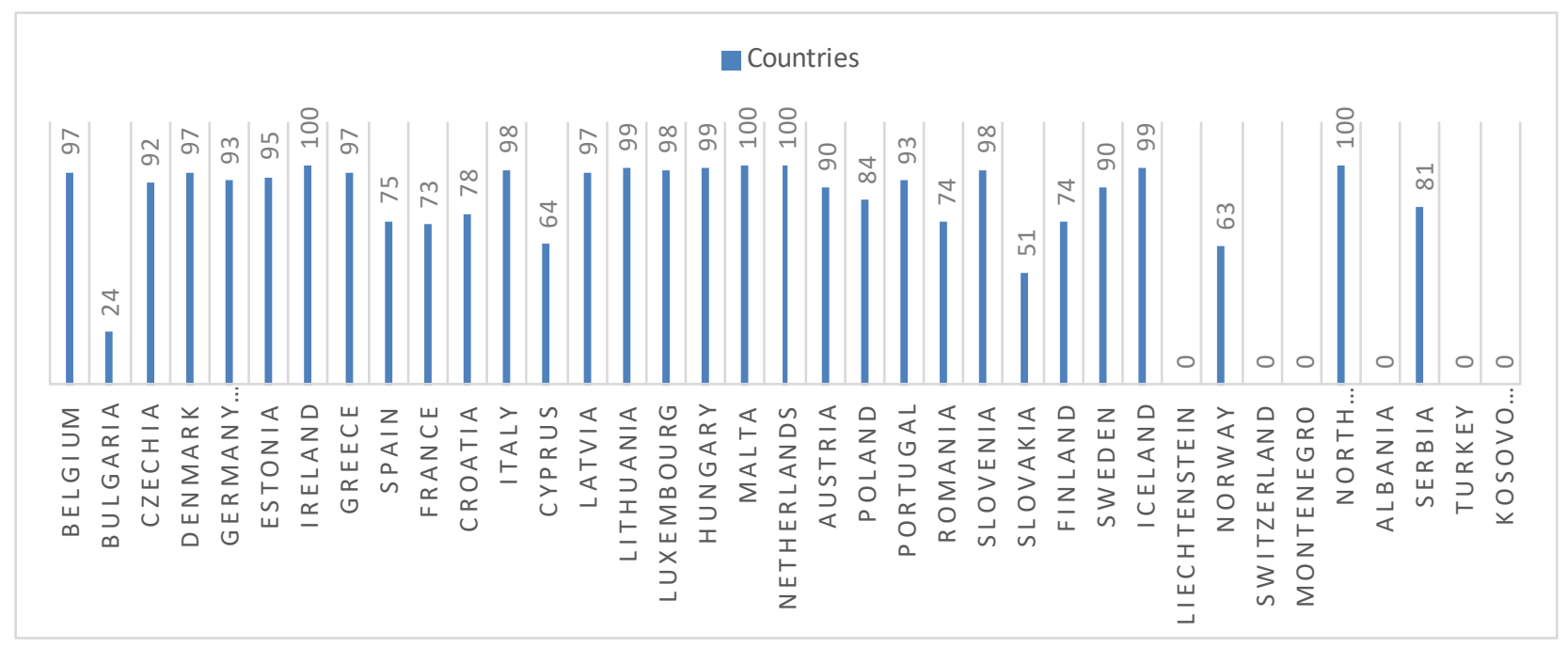

Figure 2. The recovery rate of construction and demolition waste 2018 (Eurostat, Recovery rate of construction and demolition waste, 2018)

2.1.1: Forecast-1. Based on the production index of the construction sector (EUROSTAT data series from 2005 to 2009, industry estimates from 2009 to 2013, and gross [BAU] estimates for the period 2014-2020) (Bio I. S., 2011) (Figure 3).

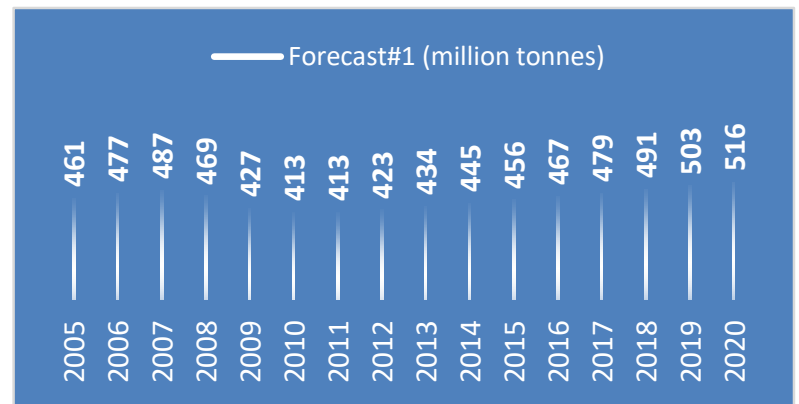

Figure 3. Forecast-1 EUROSTAT data series from 2005 to 2009, industry estimates from 2009 to 2013, and gross [BAU] estimates for the period 2014-2020) (Bio I. S., 2011)
2.1.2: Forecast - 2. It is based on assumptions on the new constructions, renovation, and demolition rates from 2005 to 2020. For this forecast, the following assumptions were made (Bio I. S., 2011):

- stable demolition rate at $0.1 \%$ per year over the considered period,

- [BAU] new construction waste of $1 \%$ per year, with a slight decrease in 2008, 2009, and 2010 due to the economic crisis,

- [BAU] renovation rate of $1.2 \%$ per year, with an increase in the period 2009 to 2011 , due to stricter energy efficiency targets,

- C \& D waste derived from demolition (25\%), renovation $(60 \%)$ and new construction (15\%) (Figure 4). 


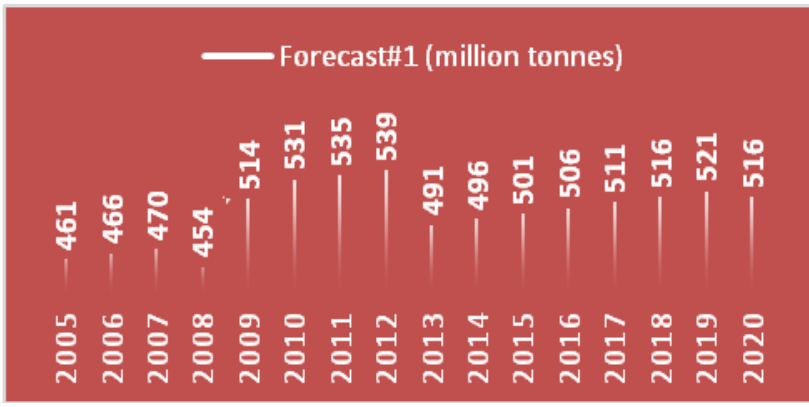

Figure 4. Forecast-2. EUROSTAT data series from 2005 to 2009, industry estimates from 2009 to 2013, and gross [BAU] estimates for the period 2014-2020) (Bio I. S., 2011)

\section{LANDFILL TREND IN EUROPEAN COUNTRIES}

\subsection{EU definition of landfill and trend of landfill}

EU definition of landfill according to identified national policies and standards: Landfill regulations: stricter control of landfilling of certain types of waste represents a major driver towards better management of $C \& D$ waste.

The landfill Directive, more formally council directive 1999/31/EC of 26 April 1999 (Commission, Ancillary legislation relating to landfill of waste, 2019), is European Union directive that regulates waste management of landfills in the European Union. It was implemented by its member states by 16 July 2001 . The directive's overall aim is to prevent or reduce as far as possible negative effects on the environment, in particular the pollution of surface water, groundwater, soil, and air, and on the global environment, including the greenhouse effect, as well as any resulting risk to human health, from the landfilling of waste, during the whole life-cycle of the landfill (European, 1999).

The landfill trend (Figure 5) on EU lands is declining. However, given the fixed trend between 2010 and 2012, as well as the slowdown trend between 2012 and 2016, it is important to look at the situation to accelerate the decline in the landfill trend in the European Union (Eurostat, Landfill rate of waste excluding major mineral wastes, 2020).

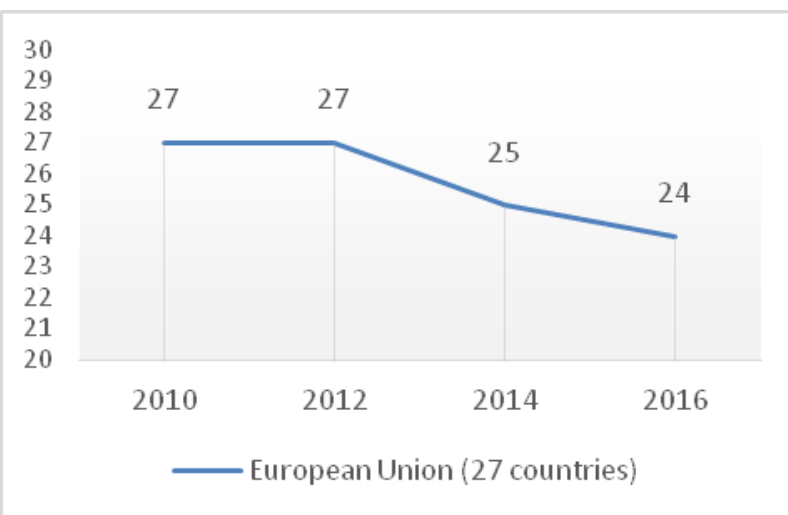

Figure 5. Landfill rate of waste excluding major mineral wastes annual, disposal-landfill (D1, D5, D12 percentage) (Eurostat, Landfill rate of waste excluding major mineral wastes, 2020)

\section{LANDFILL AND CONSTRUCTION DEMOLITION WASTE}

\subsection{The amount of material produced from construction demolition waste}

Waste generation is inevitable due to the reconstruction or demolition of the buildings. Construction, renovation, and demolition of building infrastructure can cause a lot of waste of a C\&D (Gálvez-Martos, 2018) (Table 1), which is usually either landfill in nature or abandoned in nature.

These materials can be divided into two categories according to their chemicals. In general (Government, 2019), materials caused by the destruction of constriction (Table 1) are known as $\mathrm{C} \& \mathrm{D}$, and often due to their value, they are in one of the sectors of reuse, recycle, backfill, landfill, each of which can lead to greenhouse gas emissions or environmental degradation.

However, the landfill can be considered as the most destructive of them all because without output, the product is not valuable, and the only threat is to spread all kinds of environmental pollution. Besides, it makes most of the valuable arable land that is home to animals, especially plants that produce oxygen, useless.

\begin{tabular}{cc}
\hline Waste Category & \% Min-Max Rang \\
\hline Concrete and Masonry & $84-40$ \\
\hline Concrete & $12-40$ \\
\hline Masonry & $54-8$ \\
\hline Asphalt & $26-4$ \\
\hline Others (Glass/mineral) & $9-2$ \\
\hline Wood & $4-2$ \\
\hline Metal & $4.0-2$ \\
\hline Gypsum & $0.4-0.2$ \\
\hline Plastics & $2-0.1$ \\
\hline Miscellaneous & $36-2$ \\
\hline
\end{tabular}

Table. 1. Construction and Demolition Waste composition (Gálvez-Martos, 2018)

\subsection{Inert Materials}

Inert materials are difficult to decompose in chemical reactions because at the landfill site, the environmental conditions are such that it is impossible to destroy and completely decompose them in the accumulation.

On the other hand, one of the most important factors in the decomposition of materials is microorganisms (Haider, 2019), which play an important role in the decomposition of materials.

The microorganisms break down nutrients by decomposing them. In many building materials (Figure 6), microorganisms are not fed (Jessop, 2015). Also, their high resistance to conditions such as erosion makes it impossible for them to decompose and become permeable to nature. 


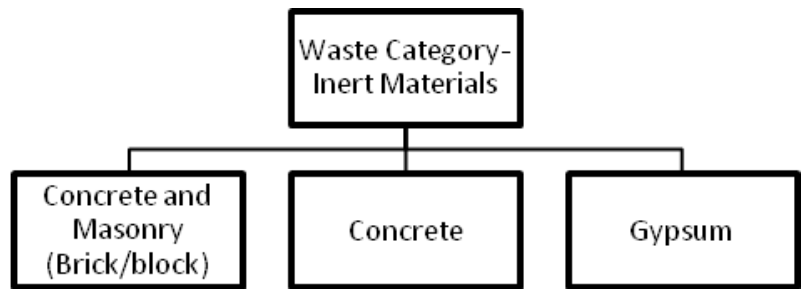

Figure 6. Inert material (Awasthi, 2019)

4.2.1: Suggestion for converting inert landfill material to reuse. Due to these materials' attributes, they can be turned into smaller pieces or powdered and used as filler in construction and construction applications. At present, the extraction of organic resources has exposed a major part of nature to the threat of raw material harvesting. Moreover, it has changed the environment and disrupted the ecology of the regions for harvesting mineral pumice and stone, which play a role in filling mortars or increasing the volume of construction work. Although these materials are natural bases, their processing methods because their original and organic nature to change, and as mentioned, they can no longer be returned to nature, although their main roots are organic matter (Figure 7).

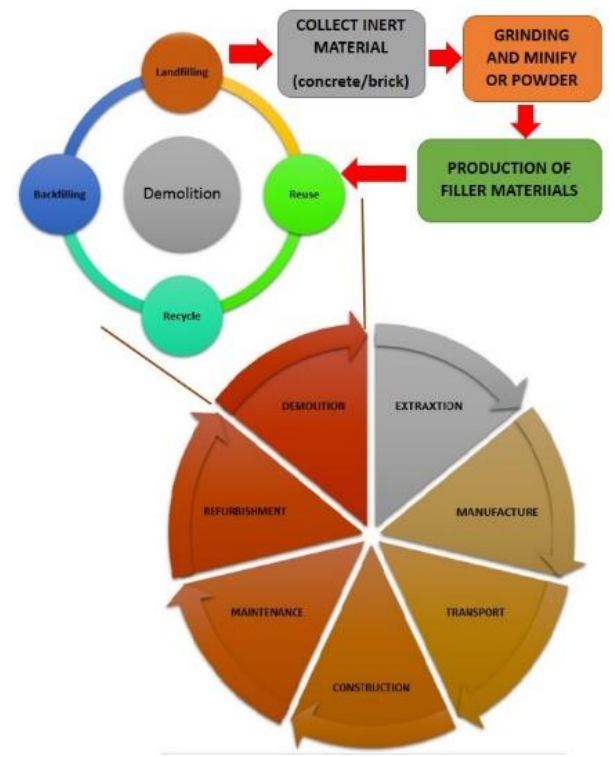

Figure 7. Life cycle of materials and extraction of materials from the landfill sector and the proposed process to return it to the reuse sector

\subsection{Non-Inert materials}

Non-Inert materials such as wood, rebar, etc., can react quickly in the environment (Awasthi, 2019), which negatively affects the environment. These materials also need fewer years to decompose, but landfilling them directly can pollute the environment (Figure 8). Although many of them are as fine as recycled glass and landfilling them requires a very long time to return to nature, they can be recovered by waste management and recycling. Moreover, they have reduced the extraction of natural resources to make new materials by recycling them.

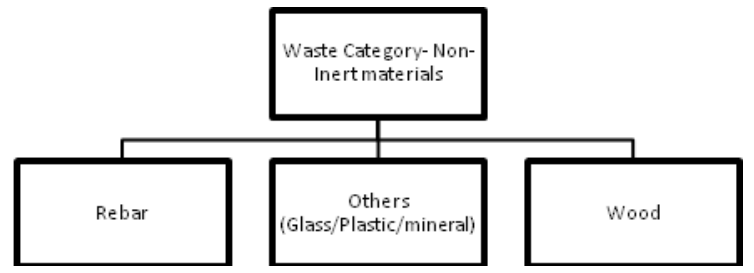

Figure 8. Non-Inert material (Awasthi, 2019)

\section{SUCCESSFUL EU POLICIES AND STRATEGIES TO REDUCE WASTE}

\subsection{Landfills in the European Union}

5.1.1: Preventing heterogeneity in recycling and burial policies. Encouragement policies to recover and recycle $C \& D$ waste clearly show that in a country like Germany, although there is no national ban on waste disposal, the high rate of $C \& D$ recycling has had directly impacted on reducing waste disposal (Figure 9).

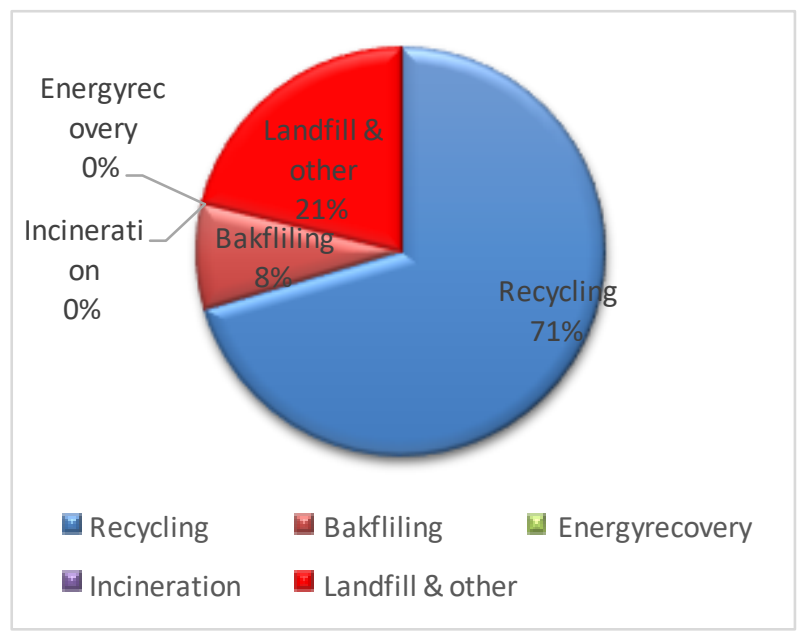

Figure 9. Mineral waste from construction and demolition waste treatment in SPAIN (Agancy, 2019) (European Environment Agency)

However, in Spain, the lack of control over the disposal of unauthorized waste and the large differences in the compilation of landfill taxes between regions as one of the main obstacles to waste recycling recovering is C\&D (Staff of the DirectorateGeneral for Environment, 2019) (Commission, Spain in Court over illegal landfills, 2015).

5.1.2: The impact of the German government's incentive policies for waste recycling and recovery. It has been proven that incentive policies for the recovery and recycling of materials (Figure 10) can be very effective in reducing the landfill of recyclable waste. Besides, it is one of the factors reducing landfills, according to which the European Union can implement incentive policies. It is important for EU member states to play a role in reducing landfills. 


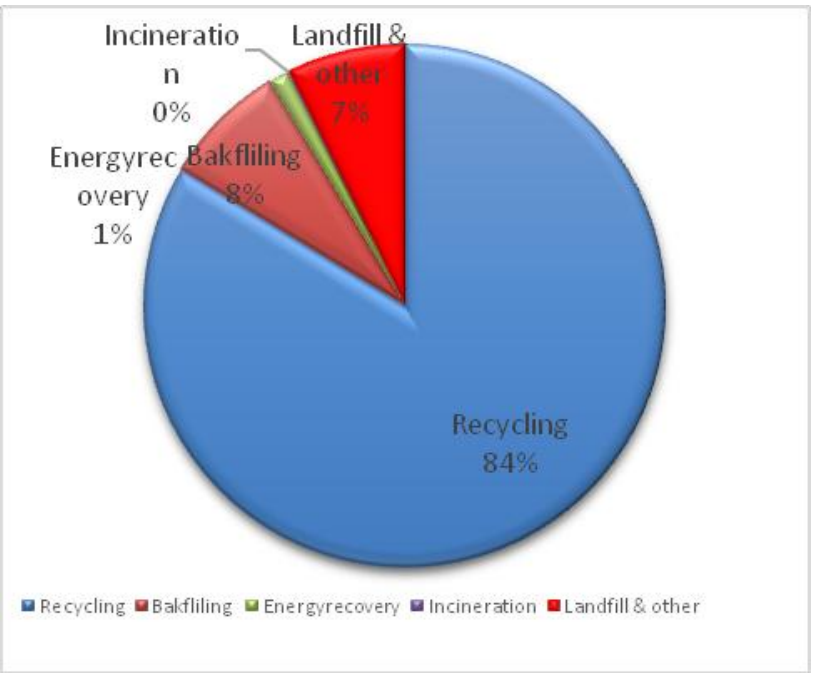

Figure 10. Mineral waste from construction and demolition, waste treatment in Germany (Agancy, 2019)

5.1.3: The impact of the Finland government's policies on Landfilling. Every year, the production of large amounts of waste in Europe and the landfill of part of it by some countries requires that the imposition of heavy taxes on the prohibition of landfilling at its recycling rate is very effective. As Finland's experience shows (Figure 11), a ban on landfills and a high tax on landfills have been the key to further recycling $C \& D$ waste. Although these rules seem easy to implement, their effectiveness depends on proper implementation and control, as well as the existence of an alternative factory network.

Currently, the toughest landfill in Finland has been adopted (Figure 11) with a ban on direct landfilling for the recyclable part of C\&D waste. Different policies and conditions can be effective in reducing landfills and encouraging recovery. In this regard, the high tax rate for landfills has been proven.

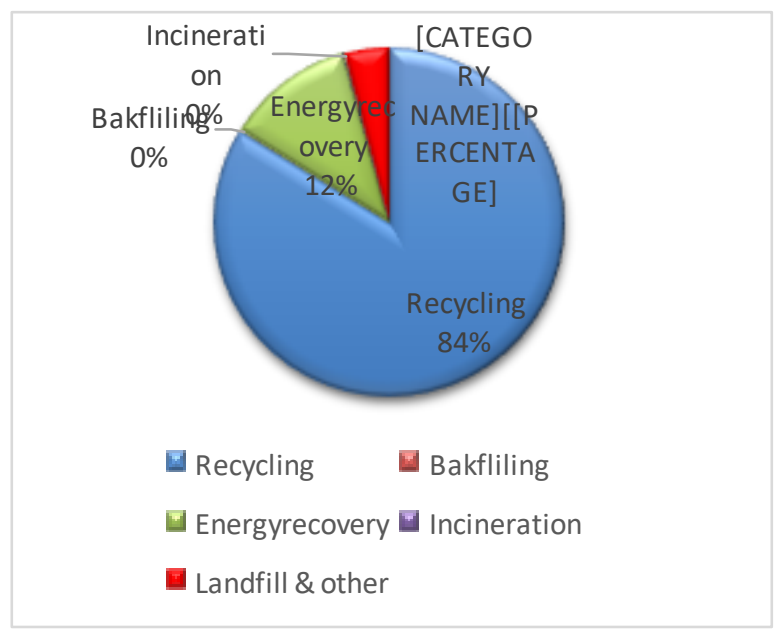

Figure 11. Mineral waste from construction and demolition, waste treatment in Finland (Agancy, 2019)

\section{CONCLUSIONS}

The mismatch between EU countries could halt EU landfill reduction as in the case of internal problems in a member state of the European Union, Spain. Also, Encouragement policies can move industries toward (CDW) recycling like the German government's recycling policies, which have clearly been effective in reducing landfills. Provided the policies adopted in Finland, it is seen that the penalties for companies that landfill waste in the environment can have a significant impact on landfill reduction. As a result, harmonizing standards and conditions for member states in a unified manner and implementing incentive policies in recycling and reusing materials can reduce the extraction of resources to supply materials and improve the recycling and reuse cycle, which will directly reduce landfills.

This result was also suggested by using non-recyclable materials as fillers in materials and new construction work. On the other hand, the further application of incentive policies for recycling and fines and heavy taxes for landfilling can play a very important role in reducing landfills in Europe, which rapidly reduces landfilling in the European Union. Reducing the landfill process prevents pollution and environmental degradation and increases the quality and health of human life, and will protect the interests and resources of the European Union.

\section{References}

Agancy, E. E. (2019). Mineral waste from construction and demolition, waste treatment. Retrieved from https://www.eea.europa.eu:

https://www.eea.europa.eu/data-and- maps/daviz/mineralwaste-from-constructiongooglechartid_chart_13.

Arm, M. W. (2015). Evaluation of the European recovery target for construction and demolition waste. In $9^{\text {th }}$ International Conference on the Environmental and Technical Implications of Construction with Alternative Materials, 31-38.

Awasthi, M. K. (2019). Sustainable Management of Solid Waste - chapter 6. Sustainable Resource Recovery and Zero Waste Approaches (pp. 79-99). Elsevier, 11-21.

Bio, i. s. (2011). In view of these fragmentary data, what could be said at the EU-27 level? In i. s. Bio, Service contract on management of construction and demolition waste - SR1 (pp. 21-240). Paris: European commission (DGENV).

Bio, i. s. (2011). Service contract on managment of construction and demolition waste-SR1-Final Report Task 2. Paris: European Commission DG ENV. 
Bio, I. S. (2011). Two approaches were taken to forecast the quantities of C\&D waste, each with its own. In I. S. Bio, Service contract on management of construction and demolition wast - SR1 (pp. 29-240). Paris: European commission (DG ENV).

Carven, P. (2015, 02 04). Are Current EU C\&D Waste Recycling Targets an Obstacle to Growth? Retrieved from www.waste-management-world.com/: https://wastemanagement-world.com/a/are-current-eu-c-d-wasterecycling-targets-an-obstacle-to-growth commission, E. (2015).

\section{DIRECTIVE OF THE EUROPEAN PARLIAMENT} AND OF THE COUNCIL-amending Directive 2008/98/EC on waste. Brussels: European commission.

Commission, E. (2015). Directive of the European parliament and of the council-Amending Directive 2008/98/EC on waste. Brussels: European Commission.

Commission, E. (2015). Spain in Court over illegal landfills. Retrieved from https://ec.europa.eu/: https://ec.europa.eu/commission/presscorner/detail/en/IP_ 15_5354.

Commission, E. (2016). EU Construction \& Demolition Waste Management Protocol. European Commission.

Commission, E. (2019). Ancillary legislation relating to landfill of waste. Retrieved from https://ec.europa.eu/: https://ec.europa.eu/environment/waste/landfill_index.htm

Craven, P. (2015, 02 04). Are Current EU C\&D Waste Recycling Targets an Obstacle to Growth? Retrieved from www.waste-management-world.com: https://wastemanagement-world.com/a/are-current-eu-c-d-wasterecycling-targets-an-obstacle-to-growth

del Río Merino, M. I. (2010). Sustainable construction: construction and demolition waste reconsidered. Waste management \& research, 4-12.

ETC/RWM. (2008). European Topic Centre on Resource and Waste Management. Retrieved from www.rec.org: https://www.rec.org/project_reference_EU.php?id=91\#: : text=European $\% 20$ Topic\%20Centre\%20on\%20Resource $\% 20$ and $\% 20$ Waste $\% 20$ Management $\% 20$

(ETC\%2FRWM),-

Name\%20of\%20legal\&text=European\%20Topic\%20Cen tres\%20(ETCs)\%20are, and\%20the\%20annual\%20manag ement\%20plans European.
E. A. (1999). Landfill Directive. Retrieved from https://www.eea.europa.eu/:

https://www.eea.europa.eu/help/glossary/eea-

glossary/landfill-directive.

Eurostat. (2015). Sustainable development in the European Union-2015 monitoring report of the EU Sustainable. European Commission.

Eurostat. (2017). Generation of waste by waste category, hazardousness and NACE Rev. 2 activity. Retrieved from https://ec.europa.eu/eurostat/home?:

https://appsso.eurostat.ec.europa.eu/nui/show.do?dataset= env_wasgen\&lang=en.

Eurostat. (2018). Recovery rate of construction and demolition waste. Retrieved from Eurostat: https://ec.europa.eu/eurostat/databrowser/view/cei_wm04 0/default/bar?lang=en

Eurostat. (2020). Landfill rate of waste excluding major mineral wastes. Retrieved from https://ec.europa.eu/: https://ec.europa.eu/eurostat/databrowser/view/t2020_rt1 10/default/table?lang=enEurostat. (n.d.). Recovery rate of construction and demolition waste. Retrieved from Eurostat:

https://ec.europa.eu/eurostat/databrowser/view/cei_wm04 0/default/map?lang=en.

Gálvez-Martos， J. L.-L. (2018). Construction and demolition waste best management practice in Europe. Resources, Conservation \& Recycling, 2-13.

Government, P. o. (2019, November). Construction Waste. Retrieved from https://www.gov.hk/en: https://www.gov.hk/en/residents/environment/waste/mana gement/constructionwaste.htm\#: :text=Inert\%20construct ion $\% 20$ waste $\% 20 \% 2 \mathrm{D} \% 20$ also $\% 20 \mathrm{known}$ waste $\% 20$ and $\% 20$ other\%20organic $\% 20$ materials.

Haider, T. P. (2019). The impact of biodegradable polymers on the environment and on society. Angewandte Chemie International Edition, 50-62.

Jessop, A. (2015, September 16). Climate Change - How is biodegradability measured? Retrieved from https://commercialwaste.trade/:https://commercialwaste.tr ade/how-is-biodegradability-measured/ Staff of the Directorate-General for Environment, E. C. (2019).

The EU Environmental Implementation Review 2019. Brussels: European Commission. 
UBA. (2009). German Environment Agency -

Umweltbundesamt - UBA. Retrieved from

Umweltbundesamt:

https://www.umweltbundesamt.de/en. 